\title{
Identificación de marcadores microsatelites polimórficos en el genoma de Dioscorea trífida L.f. "sachapapa"
}

\section{Identification of marking polimorfic microsatellites in the genome of Dioscorea trífida Lf. "sachapapa"}

\author{
Roberson Ramírez ${ }^{1}$, Pedro Adrianzén ${ }^{1,2}$, Marianela Cobos ${ }^{1}$ y Juan Castro ${ }^{1,2}$ \\ ${ }^{1}$ Centro de Investigaciones de Recursos Naturales (CIRNA) \\ ${ }^{2}$ Universidad Nacional de la Amazonia Peruana (UNAP), Apartado postal 496S Facultad de C. Biológicas
}

\section{RESUMEN}

El objetivo principal del estudio fue identificar y evaluar marcadores microsatélites polimórficos presentes en el ADN genómico de D. trífida L.f. "sachapapa". Para esto se modificó el protocolo CTAB 2X que permitió obtener ADN genómico de buena calidad con un ratio de 1,78 y una cantidad de $186,9 \mu \mathrm{g} / \mathrm{ml}$, mostrando ser aceptable para la amplificación de los microsatelites; del mismo modo se estandarizaron y amplificaron los marcadores microsatélites polimórficos, con seis pares de iniciadores, cuyos productos de amplificación variaron en un rango de 100 a 200 pb. Los 6 pares de iniciadores microsatélites utilizados no mostraron productos inespecíficos, resultando los iniciadores MTI3 y MTI10 más polimórficos con un contenido de información polimórfica (PIC) de 0,84 y 0,81 respectivamente. Sin embargo; el iniciador MTI4 resultó con menor polimorfismo con un PIC de 0,52. Se encontró una ligera dependencia entre el número de alelos diferentes y el contenido de información polimórfica (PIC) con un índice de correlación relativamente alta $\left(r^{2}=\right.$ 0,69 ). Se concluye que la técnica de obtención y purificación de ADN genómico de $D$. trífida $L$ f. es ideal para extraer ADN genómico, asimismo los 6 pares de marcadores microsatélites estandarizados son adecuados para futuros trabajos a nivel molecular en esta especie.

Descriptores: Microsatélites, Dioscorea trífida L f., ADN genómico, PIC

\section{ABSTRACT}

The main objective of the study was to identify and evaluate polymorphic microsatellite markers present in genomic DNA $D$. trifida Lf. To modify this was achieved $2 X$ CTAB protocol that yielded genomic DNA good quality with a ratio of 1.78 showing to be acceptable for the amplification and an amount of $186.9 \mu \mathrm{g} / \mathrm{ml}$ of the microsatellites, the same way were standardized and polymorphic microsatellite markers amplified with six pairs of primers, whose amplification products varied in the range of 100 to $200 \mathrm{bp}$. The 6 microsatellites primer pairs showed no nonspecific products, resulting initiators MTI10 MTI3 and more polymorphic polymorphic information content (PIC) of 0.84 and 0.81 respectively. However; the initiator was less polymorphism MTI4 with a PIC of 0.52. There was a slight dependence between the number of different alleles and polymorphic information content $(P I C)$ with a relatively high correlation index $\left(r^{2}=0.69\right)$. We conclude that the technique of production and purification of genomic DNA from $D$. trifida $L f$. is ideal for extracting genomic DNA, also the 6 pairs of microsatellite markers are adequate standard for future work at the molecular level in this species.

Keywords: Dioscorea trífida L f., Microsatellite, genomic DNA, PIC

\section{INTRODUCCIÓN}

Dioscorea trífida "sachapapa" es un tubérculo muy parecido a la papa andina y está distribuida en
África, Asia y América. En nuestra amazonia peruana constituye una fuente de primer nivel en la dieta de los pobladores nativos, colonos e incluso 
urbanos de nuestra selva alta y baja [2]. Asimismo, los estudios fisicoquímicos de harina de sachapapa [3]; revelan un $26,6 \%$ de carbohidratos, $2 \%$ de proteína y 129,5 de Energía (Kcal). El 90\% de la producción mundial de Dioscoreas está en África Central y Occidental, quienes juntamente con Nigeria, representan el $68 \%$ de toda la producción mundial. Sin embargo, en la amazonia peruana no se reporta la producción y consumo anual de la especie [1]. Además de su importancia alimenticia y económica, tiene importancia farmacológica debido a que presentan sapogeninas y pigmentos antociánicos [4]. Para D. trífida L.f., los estudios referentes a origen, distribución geográfica, variabilidad genética, y citogenético son aún escasos [5] sumado a estas deficiencias, podemos indicar la carencia de estudios moleculares de esta especie en nuestra región. Sin embargo, actualmente disponemos de diversas técnicas de biología molecular que utilizan la Reacción en Cadena de la Polimerasa (PCR) como el ADN Polimórfico Amplificado al Azar (RAPD), Polimorfismo en Longitud de los Fragmentos de Restricción (RFLP), Polimorfismo en Longitud de los Fragmentos Amplificados (AFLP) y los Microsatélites (SSR). De estas técnicas mencionadas, el estudio de los Microsatélites o SSRs se ha ido incrementando ya que muestran el más alto contenido de información polimórfica (PIC) en comparación con otras técnicas y se caracterizan por ser simples, sensibles, tener alta reproducibilidad, son codominantes y altamente informativos [6]. Además, estos marcadores microsatélites son amplificados a través de la PCR, utilizando un par de iniciadores o primers específicos, que hibridan en las regiones flanqueantes de los marcadores microsatelites.

Por las razones expuestas, se consideró como objetivo principal identificar y evaluar marcadores microsatélites polimórficos presentes en el ADN genómico de Dioscorea trífida L.f. "sachapapa", amplificando ADN purificado y cuantificando con iniciadores específicos para microsatélites e identificando los que proporcionan mayor polimorfismo.

\section{MATERIALES Y METODOLOGÍA}

\section{Área de Estudio}

Se realizó en el Laboratorio de Bioquímica de la Facultad de Ciencias Biológicas de la Universidad Nacional de la Amazonía Peruana; situada en la calle Pevas 5ta cuadra.

\section{Zona de muestreo}

Se recolectaron al azar hojas jóvenes de Dioscorea trífida $\mathrm{L} f$, del banco de germoplasma de la Facultad de Agronomía ubicado en Zungarococha $(\mathrm{km} 04$ carreretera lquitos-Nauta) cuyas coordenadas son $3^{\circ} 50^{\prime} 0504^{\prime \prime}$ de latitud y $73^{\circ} 22^{\prime} 0622$ " de altitud.

\section{Purificación de ADN genómico}

Se purificó el ADN genómico de acuerdo a [7], el cual fue modificado en los tiempos de incubación y el empleo del carbón activado, con la finalidad de eliminar los contaminantes del ADN.

\section{Determinación de calidad y cantidad de ADN}

Para verificar la calidad y cantidad del ADN se utilizaron los métodos electroforético y espectrofotométrico. Para la electroforesis se sembró $5 \mu \mathrm{l}$ de ADN genómico y se corrió en gel de agarosa al $2 \%$ teñido con bromuro de etidio $(10 \mathrm{~g} / \mathrm{ml})$, a 100V por 1 hora. Para aplicar el método espectrofotométrico se diluyó el ADN 1/20 con la relación 260/280nm. Para calcular la cantidad de ADN obtenido se utilizó la fórmula propuesta por [8]. Posteriormente se realizó el PRE- PCR con la preparación del Master Mix, que incluían agua ultrapura, buffer $10 \mathrm{X}$, dNTPs $0,8 \mathrm{mM}, \mathrm{MgCl} 22 \mathrm{mM}$, los 6 pares de iniciadores directo y reverso $0,25 \mathrm{mM}$, propuesto por [5], taq DNA polimerasa $1 \mathrm{U} / \mu \mathrm{l}$ y ADN $1 \mu \mathrm{l}$, las cantidades agregadas variaron para cada iniciador. Consecuentemente se realizó la PCR en el termociclador (TECHGENE), se realizó el corrido electroforético de los productos de amplificación en el gel de agarosa al $2 \%$, sin embargo por la poca resolución que éste presentaba se preparó en gel de poliacrilamida al $6 \%$ que permitió la separación de los alelos generados por cada iniciador. Posteriormente el gel fue teñido usando la tinción argentica con nitrato de plata propuesto por [9]. Luego se determinó el tamaño de los productos generados por la PCR en base a la ecuación de la recta generado por el RF (Índice de corrido) y el logaritmo del tamaño de cada alelo del marcador de $25 \mathrm{pb}$ (invitrogen). Finalmente se determinó el contenido de información polimórfica (PIC) según [10] para estimar a los iniciadores más informativos.

\section{RESULTADOS Y DISCUSIÓN}

\section{Calidad Y Cantidad De ADN Genómico Método Electroforético}

Al aplicar este método se observaron bandas intensas de ADN genómico. Sin embargo, inicialmente se evidenció la presencia de compuestos contaminantes del material genómico como los ARNs que se observa claramente en la parte inferior (Figura 1a), además del mucilago ubicado en los pocillos de siembra. $\mathrm{Y}$ al ser tratadas con ARNasa y carbón activado, estos contaminantes son eliminados con lo que se obtiene un ADN de 
buena calidad. (Figura 1b). Los resultados concuerdan con los resultados obtenidos por [11] y [12] debido a que utilizaron el mismo tratamiento para la extracción del ADN en hojas de Dioscorea trífida y Coffea arabica respectivamente.

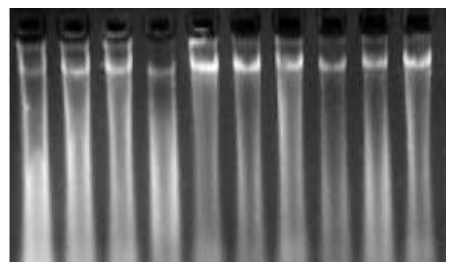

Figura 1a) Bandas de ADN genómico sin ARNasa y carbón activado b) ADN genómico tratado con ARNasa.

\section{MÉTODO ESPECTROFOTOMÉTRICO.}

En la figura 02 se observa que en cada etapa de la purificación, la absorbancia va disminuyendo conforme se van eliminando los contaminantes. En la primera etapa (E-01) se evidencia la formación de una curva (pico) indicando la máxima absorbancia de la clorofila $(660 \mathrm{~nm})$. Asimismo a $230 \mathrm{~nm}$, la absorbancia de algunos polifenoles, péptidos, hidratos de carbono, y por último las proteínas a $280 \mathrm{~nm}$. Seguidamente en la segunda etapa (E-02), el solvente orgánico Cloroformo: alcohol isoamílico y el detergente CTAB 10X en cloruro de sodio, eliminan la clorofila, polifenoles y algunas proteínas. Y en la última etapa (E-03) donde se realizó el tratamiento con carbón activado, se eliminaron en su mayoría a los contaminantes, generando solo una curva (pico) a $260 \mathrm{~nm}$, lo cual corresponde al ADN genómico. Aparentemente la presencia de las microporosidades, grupos funcionales como carboxilo, hidroxilo, carbonilo y asimismo electrones desapareados ubicados en sus centros activos del carbón activado, permitieron absorber sustancias polares como mucílago, de esta manera se optimizó y maximizó este protocolo.

Además se aprecia los ratios de calidad $\left(\mathrm{A}_{260} / \mathrm{A}_{280}\right)$ en cada una de las tres etapas de la purificación, con valores de $0,96,1,57$ y 1,75 respectivamente, estos valores reflejan la mejora en la calidad del ADN extraído conforme se avanza en las etapas de purificación. Este método registró un ratio $\left(A_{260} / A_{280}\right)$ promedio de 1,75 , aceptable con respecto al ideal $(1,8)$. Además, la concentración promedio del ADN, estimado fue de $186,9(\mu \mathrm{g} / \mathrm{ml})$. Ideal para la amplificación del marcador. Siendo este protocolo de CTAB, adecuado para extraer ADN de esta especie, sin embargo los resultados encontrados por [11] reportan al MATAB como el más eficiente, pero la concentración es mucho menor que lo encontrado con el protocolo de este trabajo.

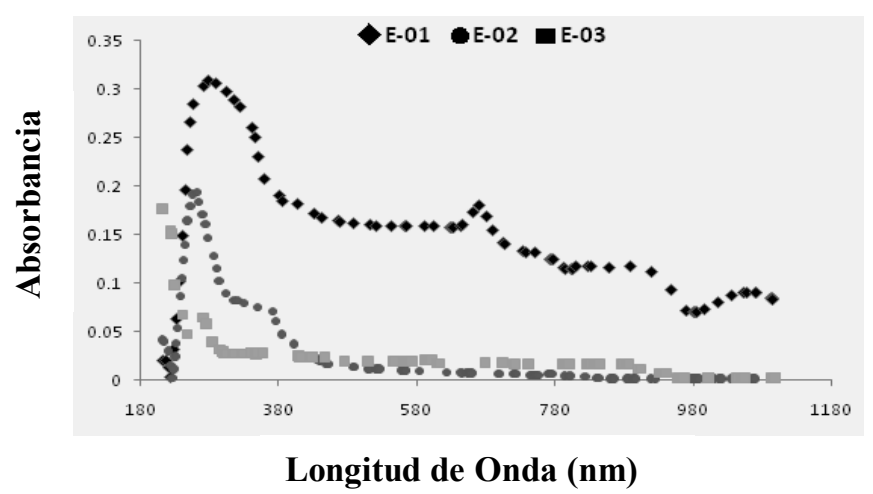

Figura 02: Análisis Espectrofotométrico de las etapas (E-01, E-02 y E03 ) del proceso de purificación del $\mathrm{ADN}$ genómico de $D$. trífida $\mathrm{L}$ f.

\section{Amplificación Con Los Seis Pares de Iniciadores Por PCR}

Los productos generados por el iniciador MTI2 Y MTI4 tienen un tamaño aproximado de $100 \mathrm{pb}$, y los productos del MTI3, MTI10 200 pb y del MTI11 y MTI12 190 pb aproximadamente (Figura 03).

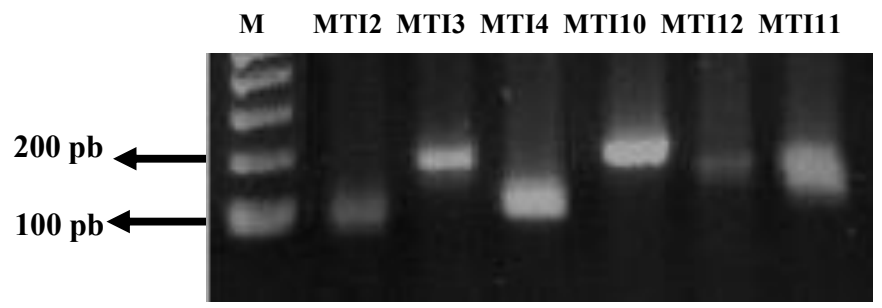

La figura 04 muestra el polimorfismo que presentan

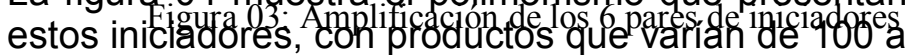
$200 \mathrm{pb}$, estos tamaños encontrados también fueron reportados por [5]

Muestras 1 -9

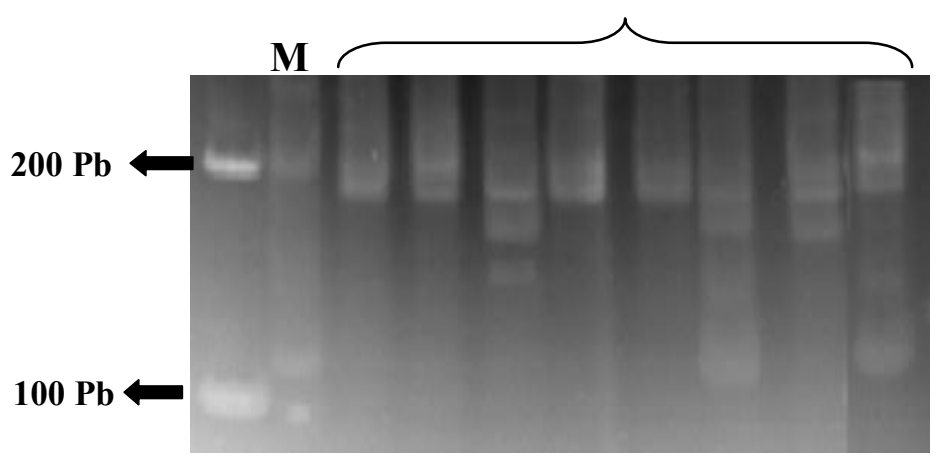

Figura 04: Iniciador más polimórfico MTI3 


\begin{tabular}{|c|c|c|c|c|}
\hline Iniciadores & $\mathrm{R}^{2}$ & Ecuación & $\begin{array}{c}\text { Rangos } \\
(\mathrm{Pb})\end{array}$ & $\begin{array}{c}\text { Rangos } \\
\text { (Hochu } \\
\text { et al. } \\
2006)\end{array}$ \\
\hline MTI12 & 0,995 & $\begin{array}{c}\mathrm{y}=-0,751 \mathrm{x}+ \\
2,721\end{array}$ & $105-123$ & $101-125$ \\
\hline MTI2 & 0,998 & $\begin{array}{c}\mathrm{y}=-0,825 \mathrm{x}+ \\
2,691\end{array}$ & $120-129$ & $119-131$ \\
\hline MTI11 & 0,997 & $\begin{array}{c}\mathrm{y}=-0,754 \mathrm{x}+ \\
2,701\end{array}$ & $141-155$ & $127-145$ \\
\hline MTI4 & 0,999 & $\begin{array}{c}\mathrm{y}=-0,565 \mathrm{x}+ \\
2,497\end{array}$ & $107-117$ & $101-118$ \\
\hline MTI3 & 0,998 & $\begin{array}{c}\mathrm{y}=-0,845 \mathrm{x}+ \\
2,699\end{array}$ & $138-191$ & $131-204$ \\
\hline MTI10 & 0,999 & $\mathrm{y}=-0,922 \mathrm{x}+$ & $151-174$ & $158-178$ \\
\hline
\end{tabular}

\section{Contenido de Información Polimórfica (PIC)}

El iniciador MTI3 presenta mayor (PIC) con un valor de 0,84; es decir tiene más capacidad de discriminar los loci (Figura 1b), seguida del iniciador MTI10, con PIC de 0,81; por otro lado el iniciador MTI4 tiene menor valor PIC con 0,52 y el iniciador MTI2 con 0,58 . Estos resultados concuerdan con lo reportado por [5] que reporta al iniciador MTI3 y MTI10 como más polimórfico. Asimismo, reporta al iniciador MTI11 como menos informativo, sin embargo en este trabajo se obtuvo como menos informativo al iniciador MTI4 con un PIC de 0,52, seguido del iniciador MTI2 que si concuerda con los reportes de [5], así como el rango de tamaño y número de alelos encontrados.

\section{Relación entre contenido de información polimórfica y número de alelos diferentes.}

Existe una ligera relación lineal debido a que se encontró un índice de correlación relativamente alto $\left(r^{2}=0.69\right)$, entre el número de alelos generados por cada iniciador y el contenido de información polimórfica (PIC) de cada iniciador, es decir existe una ligera dependencia del número de alelos diferentes para un mayor valor de PIC.

El cuadro 01 muestra la ecuación de la recta y los valores de coeficiente de correlación lineal $\left(R^{2}\right)$ generados a partir del marcador ladder de $25 \mathrm{pb}$ por cada iniciador. Esta ecuación permitió obtener el tamaño de los alelos generados por cada iniciador. Y estos resultados concuerdan con los reportados por [5]
Tabla 01: Datos de Índice de Correlación $\left(r^{2}\right)$, ecuación de la recta de cada Iniciador y los rangos encontrados con cada iniciador y los propuestos por Hochu et al. (2006).

\section{CONCLUSIONES}

Se obtuvo ADN genómico de Dioscorea trífida L.f. de buena calidad 1,75 de ratio y cantidad con 186,9 $\mu \mathrm{g} / \mathrm{ml}$ promedio, suficiente para ensayos de amplificación.

El Marcador o iniciador MTI3 presentó mayor polimorfismo con un PIC de 0,84 y por tanto es el más informativo, seguido del marcador MTI10 con PIC de 0,81 y el menos polimórfico e informativo es el MTI4 con un PIC de 0,52.

Se logró estandarizar y amplificar los 6 pares de iniciadores 0 marcadores microsatélites, demostrándose que son reproducibles debido a la presencia de los productos esperados

\section{AGRADECIMIENTOS}

Al proyecto "Selección de clones superiores de Dioscorea trífida L. f; (Sachapapa) en base a su caracterización morfológica, molecular y fotoquímica, de la Región Loreto" por el financiamiento a este trabajo de investigación

A la Facultad de Ciencias Biológicas de la Universidad Nacional de la Amazonia Peruana, por permitir el acceso a sus ambientes y uso de equipos para el desarrollo de este trabajo.

\section{REFERENCIAS}

[1] FAO. FAOSTAT Agriculture data. (2002) http://apps.fao.org/collection

[2] Montaldo A. Cultivo de Raíces y tubérculos (1991).2da. Edición

[3] Reátegui d; Maury m: Chirinos c; Aricaria I. Revista Amazónica de Investigación

Alimentaria. 1(2001)43-48.

[4] Heble M. R; y Staba E. Planta Medica supplement (1980) Pp. 124-128

[5] Hochu, I. ; Santoni, S. Busalem, M. Journal Molecular Ecology 6(2006) 137-140 
[6] Ramos S.; Barrios A.; A. Martin; Garcia A.; Rodríguez M.; Hernández M.Barriuso B.; Caminero $\mathrm{C}$. Tecnológico Agrario de Castilla y León (ITACyL) 2(3): 21 - 24

[7] Ghislain M. Rodríguez F.; Villalón F.;.Nuñez J.; Waugt R.; Bonierbale M. Centro Internacional de la Papa (CIP). Program rep. (2000)Pp. 167 - 174

[8] Sambrook et al. Molecular cloning. (2001).Third edition.

[9] Bassam Y Gresshoff Nature protocols Recipes for Researches 2(2007)3-4

[10] Bolsteind D.y Whiter.R; L. American Journal of Human genetic. 32(1980) 314 - 315.
[11] Gonzales Y. Agropecuaria de Panamá, IDIAP y CATIE. (2003) Pp. $68-69$.

[12] Krizman M; Jaksej J; Baricevic, Javornik B. Acta agriculturae Slovenica, 2(2006) 427 439.

[13] Morales, R.; Gonzales, C; Gonzales, R; Hernández, R. Notas de investigación en progreso. IDIAP. 11(2001)1: 9

Roberson_leo@hotmail.com 